\title{
Modelling the impacts of projected future climate change on water resources in north-west England
}

\author{
H.J. Fowler ${ }^{1}$, C.G. Kilsby ${ }^{1}$ and J. Stunell ${ }^{2}$ \\ ${ }^{1}$ Water Resource Systems Research Laboratory, School of Civil Engineering and Geosciences, Newcastle University, Newcastle upon Tyne NE1 7RU, UK \\ ${ }^{2}$ Water Resources Regulatory and Technical Team, Environment Agency, NW Regional Office, Warrington, UK [Now at JBA Consulting, The Brew House, \\ Wilderspool Park, Greenall's Avenue, Warrington, UK
}

Email for corresponding author: h.j.fowler@ncl.ac.uk

\begin{abstract}
Over the last two decades, the frequency of water resource drought in the UK, coupled with the more recent pan-European drought of 2003, has increased concern over changes in climate. Using the UKCIP02 Medium-High (SRES A2) scenario for 2070-2100, this study investigates the impact of climate change on the operation of the Integrated Resource Zone (IRZ), a complex conjunctive-use water supply system in north-western England. The results indicate that the contribution of individual sources to yield may change substantially but that overall yield is reduced by only $18 \%$. Notwithstanding this significant effect on water supply, the flexibility of the system enables it to meet modelled demand for much of the time under the future climate scenario, even without a change in system management, but at significant expense for pumping additional abstraction from lake and borehole sources. This research provides a basis for the future planning and management of the complex water resource system in the north-west of England.
\end{abstract}

Keywords: water resources, drought, north-west England, UKCIP02, regional climate model, climate change impacts

\section{Introduction}

In the UK, in the late 1980s and early 1990s, as a recurrent outcome of increased hydrological seasonality (Marsh and Monkhouse, 1993), the frequency of droughts has increased (Bryant et al., 1994; Marsh and Turton, 1996) and culminated in the severe drought of 1995-96 which affected mainly the north and west of the country (Marsh, 1996). The recent pan-European drought of 2003 increased concern that climate is changing and, under global warming, large increases in temperature variability during the summer months have been suggested (Schär et al., 2004). Additionally, current trends in UK rainfall (Fowler and Kilsby, 2002) and future projections from Global Climate Models (GCMs) suggest that winters will, on average, become wetter and summers drier (Giorgi et al., 2001a,b; Hulme et al., 2002); the UKCIP02 scenarios (Hulme et al., 2002) indicate that, by the 2080 s, summer reductions as high as $50 \%$ and winter increases of $30 \%$ may occur. However, more importantly, under global warming, climate models indicate increases in the future frequency and magnitude of extreme events (McGuffie et al., 1999). By the end of the century, a 10-30\% increase in the magnitude of UK rainfall events up to a 50-year return period (Fowler et al., 2007; Ekström et al., 2005) has been predicted as well as an increase in the severity and frequency of droughts of 3- and 6-month duration, particularly in the south-east (Fowler and Kilsby, 2004). Such changes would have serious implications for the future management of water resource systems.

Increases in seasonal rainfall contrasts as well as extreme events, such as the droughts in the 1990s (Marsh, 1996) and the floods of 2000/01 (Marsh, 2001), affect the water balance of river basins severely. They also influence the availability of water resources, as well as the frequency of flooding and of ecologically damaging low-flows. Despite numerous studies of the effects of climate change on hydrological regimes, few have considered the impact of climate change on a complex water resource system such as that described by Fowler et al. (2003); many have concentrated on modelling simple systems such as individual 
storage reservoirs (Vogel et al., 1999; Lane et al., 1999; Maier et al., 2001; Kay, 2000), although some US studies have considered both sophisticated downscaling methods and the modelling of complex water resource systems (Christensen et al., 2004; Payne et al., 2004; VanRheenen et al., 2004). Most, however, addressed only changes in mean climate, using the 'perturbation method' (Prudhomme et al., 2002) to alter the observations input to a hydrological model on a monthly, seasonal or annual basis according to future changes projected by GCMs (Arnell, 1992; Arnell and Reynard, 1996; Hewett et al., 1993; Wardlaw et al., 1996; Pilling and Jones, 1999, 2002). Within the historic record, this allows examination of changes to mean flows without separate consideration of changes in variability (extremes) or sequences of storms and dry periods (Wood et al., 1997). However, it is precisely these that will have the greatest effect on hydrological processes (Burlando and Rosso, 2002a,b; Arnell, 2003).

Much of the north of England relies on surface water resources because the geology of the north-west results in groundwater storage potential of only 15\% (Fowler et al., 2003; Walker, 1998). Therefore, short-term summer drought, as well as longer droughts such as that in 1995-96, can have an extremely detrimental effect on water supplies (Marsh, 1996) in the Integrated Resource Zone (IRZ) of United Utilities. This network of impounding reservoirs, river and lake abstractions, inter-river transfers and groundwater abstractions is linked to the major urban centres through major aqueducts (Walker, 1998). Rainfall, mainly from weather systems in the westerly quadrant, leads to a seasonal flow regime, with the runoff largest in winter and spring and least in summer. During the 1995-96 drought, the most severe in the historic record, the 18-month rainfall of only $56 \%$ of the long-term average caused reservoirs to be at their lowest historic levels in the spring of 1996 (Walker, 1998). Despite the success of management in avoiding severe restrictions on water supply throughout the 199596 drought, the need to quantify the likely effects of climate change on the IRZ was highlighted as a priority.

This paper examines the effect of future climatic change upon the performance of the north-western England IRZ using the Medium-High UKCIP02 climate change scenario (Hulme et al., 2002); based on the A2 SRES emissions scenario (IPCC, 2000). Daily rainfall and temperature data from the HadRM3H Regional Climate Model (RCM) have been used to drive the UKCIP02 scenarios directly as input to catchment models. Such a direct input of dynamically downscaled RCM data to hydrological models has been successful in representing historic inflows in US studies (Wilby et al., 2000; Hay and Clark, 2003; Wood et al., 2004). In north-west England, this method reproduces the statistical distribution of historic flows (Fowler and Kilsby, 2007). Compared to statistical downscaling, RCMs produce spatial patterns of climate variables, such as rainfall and temperature which, while more homogenous, may be no more realistic (Cubasch et al., 1996; Mearns et al., 1999). However, the direct input of RCM data to hydrological models in impact studies allows proper consideration of changes in variability (extremes) or sequences of storms and dry periods, the variables that most affect hydrological processes.

This analysis, representing the state of the art in the assessment of the potential impacts of climatic changes on water resource systems, builds on the methodology developed by Fowler et al. (2003) but uses dynamical rather than statistical downscaling to provide inputs to the hydrological models. Here, the 'perturbation method' is improved and changes to mean rainfall amount, spatial patterns, sequencing and variability are incorporated in the analysis by the direct use of 'bias-corrected' RCM data. This study provides not only an insight into the potential impact of future climate changes on the performance of the northwest England IRZ but also a robust and repeatable methodology for the modelling of such climatic impacts on complex water resource systems.

\section{The north-west England Integrated Resource Zone (IRZ)}

The water supply system in north-west England can be classified into complex, linked systems and stand-alone sources. Here, modelling will be confined to the IRZ, which provides $56 \%$ of freshwater public supplies to industrial, commercial and domestic customers in the region (Walker, 1998). An interconnection of major aqueducts links sources (impounding reservoirs, river abstractions etc.) with demand centres (Fig. 1). Thus, Thirlmere and Haweswater impounding reservoirs in the Lake District, and sources in Lancashire, the River Lune abstraction and Stocks reservoir, are linked to the Manchester conurbation and central and east Lancashire through the Thirlmere and Haweswater aqueducts. Similarly, Liverpool and the southern part of the region are served by aqueducts from Vyrnwy reservoir and the River Dee in north Wales in addition to groundwater sources. The Rivington aqueduct is bi-directional, enabling water from the rivers Dee and Vyrnwy to be transferred to Greater Manchester and water from Thirlmere and the river Lune to be transferred to the Liverpool area. The Pennine region is served mainly by local sources such as the Longdendale reservoir group backed up by supplies from the Lake District aqueducts. In this study, the eight largest individual sources which are modelled comprise six impounding reservoirs, Haweswater, Thirlmere, Rivington, 


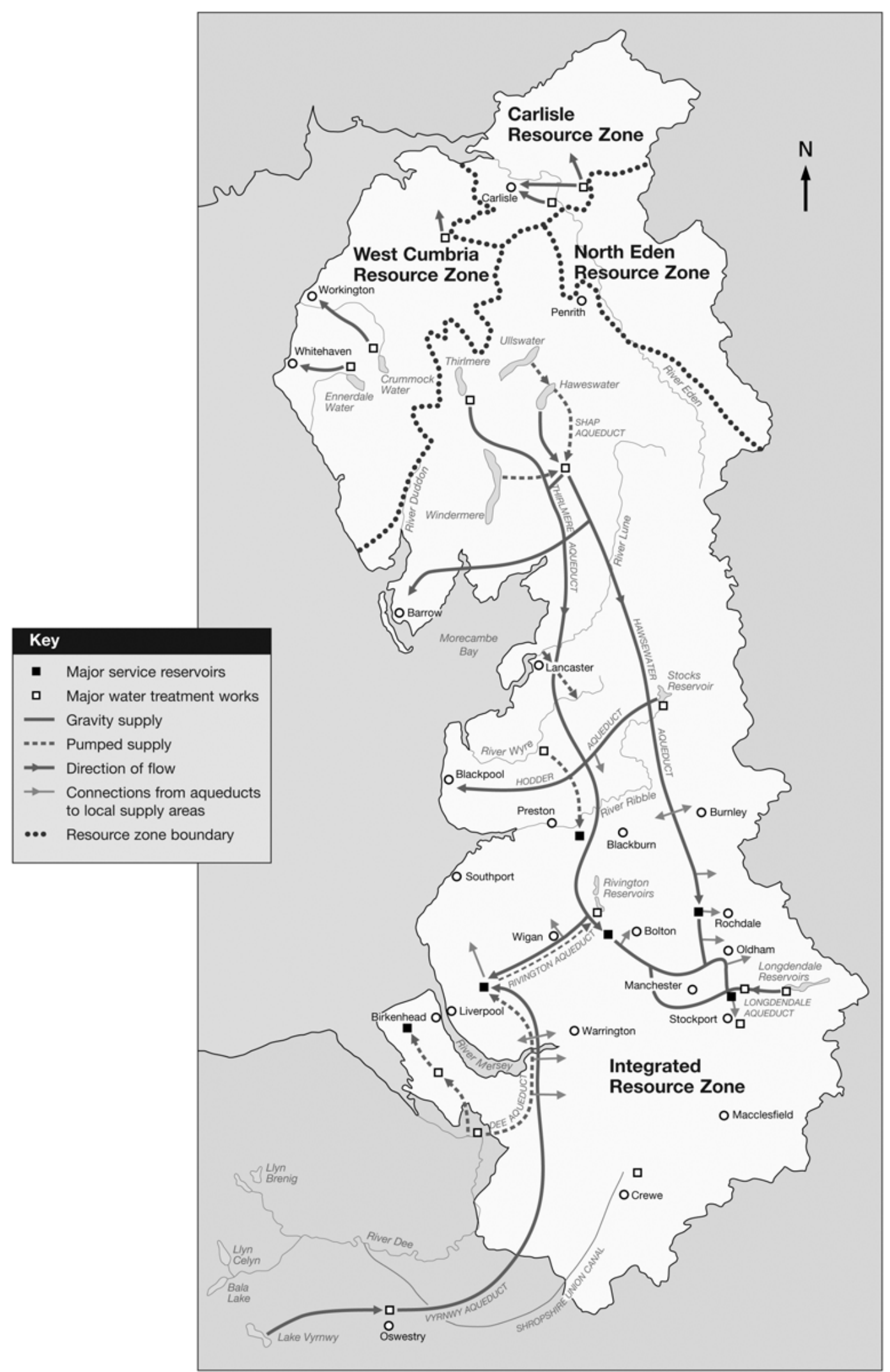

Fig. 1. The study area, showing the six north-west reservoired catchments of Thirlmere, Haweswater, Stocks, Longdendale, Rivington and Lake Vyrnwy and the rivers Lune and Dee. The white area denotes the NW integrated resource zone, with the additional water resources of Lake Vyrnwy and the river Dee lying in north Wales to the west (from Fowler and Kilsby, 2007, their Figure 1). 
Stocks, Longdendale (the largest individual source in the Pennine South group) and Vyrnwy; and abstractions from the rivers Lune and Dee; other inflows derived from these sources are determined using regression relationships.

\section{Data}

\section{CLIMATE VARIABILITY AND CHANGE SCENARIOS}

The HadRM3H RCM, developed at the Hadley Centre of the UK Met Office was derived from the HadCM3 (Gordon et al., 2000; Johns et al., 2003) GCM. HadRM3H integrations were used to produce the new UKCIP02 climate change scenarios for the UK (Hulme et al., 2002). Boundary conditions are derived from the global atmosphere model, HadAM3H, (Pope et al., 2000) which is intermediate in scale between the coarser resolution HadCM3 and HadRM3H. An ensemble of three integrations has been run for a reference baseline or 'control' period (1960-1990) using observations of sea-surface temperatures (SST) and sea-ice instead of their HadCM3-modelled counterpart (Hulme et $a l ., 2002)$. The three integrations have similar long-term characteristics but show significant year-to-year and decadeto-decade differences due to internal climate variability. An ensemble of three integrations has also been produced for a future period (2070-2100) based upon the IPCC A2 SRES (Special Report on Emissions Scenarios) 'storyline' (IPCC, 2000) (the UKCIP02 Medium-High Emissions scenario) and driven by changes in the SST and sea-ice predicted by HadCM3 added to the observations. This combination of models gives a more realistic representation of the North Atlantic storm track compared to the use of a GCM alone (Hulme et al., 2002) but has the disadvantage that only the A2 SRES emissions scenario and the period 2070-2100 are simulated.

\section{SIMULATING RAINFALL, PE AND HYDROLOGIC} INPUTS

Rainfall and potential evapotranspiration (PE) series were produced using a methodology detailed in Fowler and Kilsby (2007). Daily rainfall and temperature series were extracted from the HadRM3H model for grid cells corresponding to the six impounding reservoir and two river sources for both the control and future scenarios. However, the control scenario data underestimated the historic mean rainfall significantly as well as over-emphasising seasonality, with wetter winters and drier summers. Even when corrections were made for differences in elevation (Fowler and Kilsby, 2007), errors were in excess of $50 \%$ in some months in some catchments, Additionally, high temperatures were over- estimated when compared with observations (Fowler and Kilsby, 2007). These 'biases' in RCM data have been noted elsewhere (Wilby et al., 2000; Hay and Clark, 2003; Wood et al., 2004) and 'bias-correction' of RCM data is deemed necessary to produce realistic sequences of streamflow (Wood et al., 2004).

The standard practice for dealing with corrections to modelled climatic variables has been to apply monthly factors based on the ratio of the control climatology to observed values on a grid box basis as in Durman et al. (2001) although Wood et al. (2004) developed a more sophisticated method, using 'quantile-based mapping' of the control scenario data onto the observed distribution for bias removal. Here, the Durman et al. (2001) approach was used and 'bias-correction' (B-C) was performed on the control scenario rainfall and temperature data such that the modelled monthly average in the control climate matched the monthly average observed over the period 1961-90. The same B-C factors were then applied to RCM data for the future scenario. This approach corrects only the monthly climate means and does not consider corrections to the variability by the Wood et al. (2004) 'quantile-mapping' approach. This simpler modification of mean monthly climate was adequate for simulating the control climate to represent observed climatic statistics such as variability and skewness (Fowler and Kilsby, 2007) without placing further constraints on the correction of the future scenario by assuming that the rainfall distribution will be approximately the same in a future climate.

The Blaney-Criddle approach (Blaney and Criddle, 1950) was used to calculate PE for the control and future scenarios (Ekström et al., 2007b). This assumes that the coefficients of an empirical Blaney-Criddle equation based on an historic 1961-1990 monthly relationship between temperature and PE (Walsh and Kilsby, 2007) can be extrapolated to a future climate. The equation is given by Walsh and Kilsby (2007).

$$
P E T_{t}=p_{t}(\alpha T+\beta),
$$

where

$$
\begin{aligned}
& P E T_{\mathrm{t}}=\text { PET estimated by Penman-Monteith formulation } \\
& p_{t}=\text { mean daily percentage (for the month) of total } \\
& \quad \text { annual daytime hours } \\
& \alpha=\text { empirically derived, } 0.456 \\
& \beta=\text { empirically derived, } 0.416 \\
& T=\text { temperature in }{ }^{\circ} \mathrm{C}
\end{aligned}
$$

$\mathrm{PE}$ for the control and future simulation of HadRM3H was then computed using the above relationship, but substituting bias-corrected daily temperatures from HadRM3H into the equation to estimate daily PE values. 
For the control scenario, the B-C rainfall data provided a good match to observed (1961-90) rainfall statistics, although the variance is under-estimated slightly by the simulated data, as was noted by Hay and Clark (2003). The calculated PE data for the control scenario also well matched that calculated using observed temperature values.

A simplified version of the Arno hydrological model (Todini, 1996) was then used to translate the rainfall and PE data into streamflow series that could be used as input to the water resource system model. Model calibration for each catchment was achieved using a method of genetic algorithm optimisation, the shuffled complex evolution method for global optimisation (SCE-UA), developed by Duan et al. (1992), with the Nash and Sutcliffe 'efficiency' measure (CE) (Nash and Sutcliffe, 1970) as the optimisation criterion. Historic rainfall, $\mathrm{PE}$ and flow data from the period 1961-90 were used in a split-sample calibration and validation. CE values ranged from 0.58 to 0.76 and the water balance was within $7 \%$ of the derived historical inflows in all cases (Fowler and Kilsby, 2007).

Daily flow sequences were produced in this way for each catchment for both the control and future scenarios using the $\mathrm{B}-\mathrm{C}$ rainfall and $\mathrm{PE}$ data series as input to the calibrated ADM catchment models. This gave 92 years of flows for both the control and future scenarios respectively, with the first year of simulated flows being discarded as a model 'warm-up' period. Figure 2 shows the monthly percentage change in runoff between the control and future simulations at Haweswater, Longdendale and the lower Dee. These respectively represent other sources in the Lake District, Pennines and Wales, as other sources behave in a similar way under the future climate scenario.

As simulated flows are derived using output from a regional climate model and are thus synthetic, then droughts and other events would not be expected to occur in the same sequence as during 1961-90; rather, the average flow statistics are the same as those observed during 1961-90. The ADM model parameters are used unchanged for the future impact assessment. This assumes that there are no significant changes in land use or hydrological response for the future scenario.

\section{Modelling approach and results}

\section{THE MOSPA WATER RESOURCE MODEL}

To examine the performance of the IRZ under climatically changed conditions, the Mospa model was used and the outputs of the water resource system were evaluated with reference to an imposed demand.

Mospa is a complex water resources planning model of
United Utilities and the UK Environment Agency using components such as demand zones, reservoirs, boreholes, river abstractions and treatment works. These are connected by a network of pipes which move water around the system from the sources to the demand zones via the treatment works.

Mospa allows assessment of the performance of the entire IRZ water resource system, taking account of restrictions such as abstraction licence conditions, pipe capacity and treatment works. This allows a conjunctive use element (Wood et al., 1997; Lettenmaier et al., 1999) to be defined as, although the reliability, resilience and vulnerability of water sources within a system can be determined on an individual basis, shortages in supply may occur only when shortfalls are concurrent at more than one source.

Mospa can be used for several types of run including a basic simulation for a specified period and a yield search in which the model iterates demand on the system to find the maximum yield of the system (i.e. the largest demand on the system that can be met throughout the length of the run without deficits). It can also be used to optimise control rules.

The model requires a number of inflow sequences. Inflows to the major sources (6 impounding reservoirs and 2 rivers) were derived using the climate change model as detailed above. Other inflows were factored from control and future flows modelled at nearby sites. Additionally, at two minor sites, average data were substituted into both the control and future scenarios as no suitable sites were available to factor the flow.

\section{MODELLING APPROACH}

Water resource system behaviour in the IRZ is examined using Mospa for: (a) control climate using bias-corrected RCM data for the 'baseline' period 1961-1990, and (b) a future climate scenario (UKCIP02 Medium-High or SRES A2) for the period 2070-2100. In each case two runs were performed: (i) a basic simulation with demand specified as $2224 \mathrm{Ml} \mathrm{d}^{-1}$, and (ii) a yield search, with all resources starting full and based on control rules used by United Utilities in November 2003, a period when the north-west region was suffering from drought conditions. These control rules aim to conserve storage in Haweswater and Thirlmere.

An initial run was carried out using observed inflows for the period 1961-1990 to check that the model control run accurately simulates the observed 'baseline' period. The yield obtained, $2313 \mathrm{Ml} \mathrm{d}^{-1}$, is $98 \%$ of the control scenario yield, $2358 \mathrm{Ml} \mathrm{d}^{-1}$. Therefore, the control run is deemed to simulate the observed 'baseline' adequately. However, yield calculations by United Utilities and the Environment Agency 
Haweswater

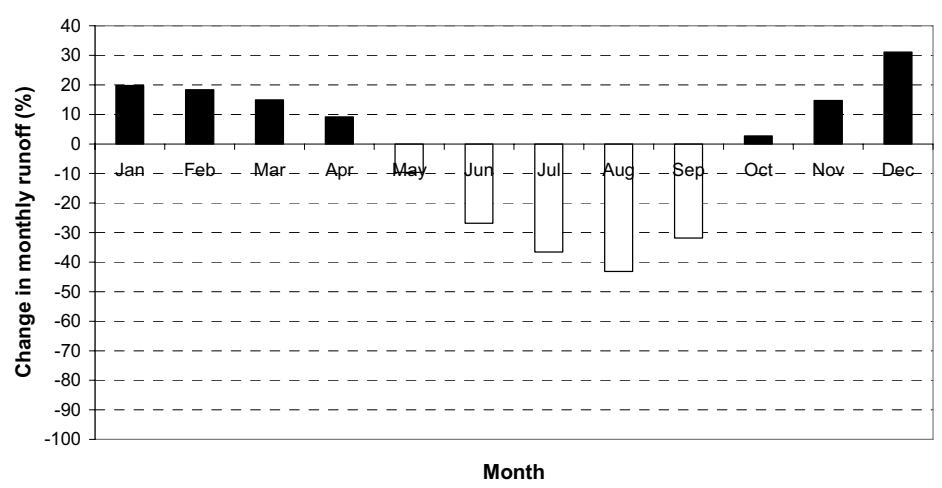

Longdendale

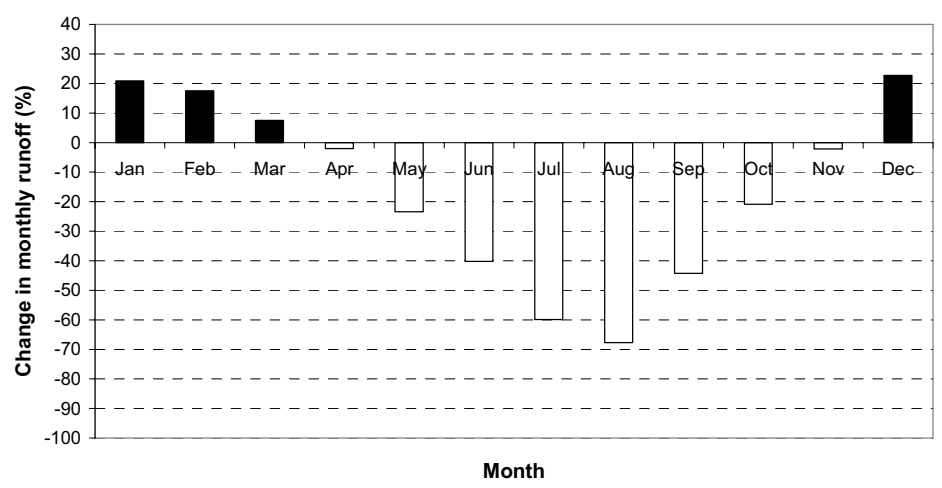

Lower Dee

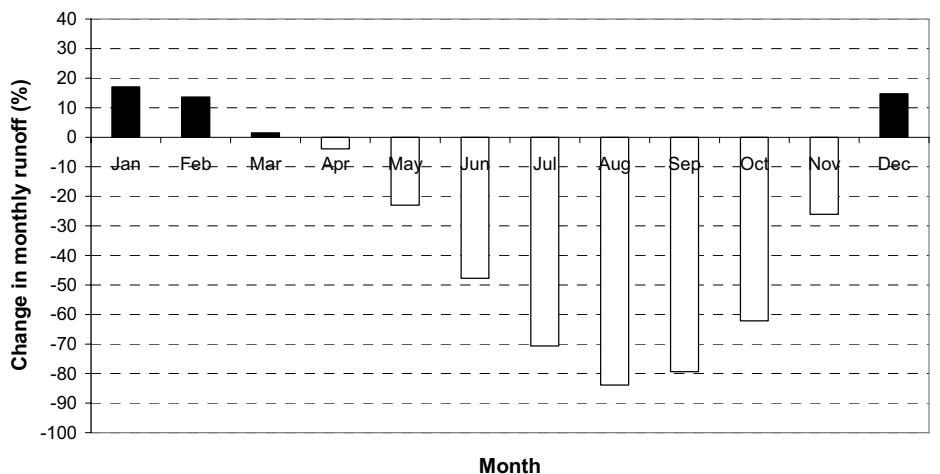

Fig. 2. Percentage change in monthly runoff between the HadRM3H control and future scenarios.

are based on the full record period from 1927-2002 rather than the 30-year period from 1961-1990 used in this study.

For the basic simulation and the yield search, monthly model outputs from both the control and future scenarios were analysed on the basis of overall system yield available and on data on the performance of individual sources. The model outputs included: average end of month storage, total spill and compensation releases, average abstraction and the percentage of total abstraction for individual sources, including reservoirs, boreholes and rivers. However, drought water use restrictions are imposed by the model when the combined storage at the Haweswater and Thirlmere reservoirs drops below a certain amount, temporarily reducing the demand to be met.

A caveat to this modelling approach must be noted. Here, the future scenario has been run using the same control rules as the 'baseline' run. In practice, control rules may well be modified under conditions of climate change and, in 
addition, adjusting the control rules for individual sources would probably increase the overall system yield. However, this study is aimed at indicating how the system may respond to the medium-high UKCIP02 climate change scenario and at suggesting which control rules need to be changed to adapt to this possible scenario of climate change. Further, more detailed, analysis will allow control rules to be changed to develop a more sustainable strategy.

\section{Results}

\section{BASIC SIMULATION}

Table 1 shows the results for the basic simulation run for the control scenario, with no drought restrictions imposed through the entire period. In contrast, in the future scenario simulation, the system failed to meet demand in three periods: two in October, when it was unable to meet demand from the river Dee and one in March, when it was unable to meet the requirement for river flow release from Vyrnwy reservoir. Also, drought restrictions were imposed during the future scenario simulation for 39 days during one autumn period.

Under the future scenario, there is a substantial decrease in the minimum storage of the reservoirs (not shown). Although the number of days that the reservoirs' spill is lower under the future scenario, the maximum flow downstream of Windermere and Ullswater (lake sources) is higher (Table 1). This suggests that, under the future scenario, more high flow events may occur.

In terms of river abstractions, there is a significant reduction in the minimum abstraction from the River Dee under the future scenario, although the average abstraction is similar (Table 1). Abstraction from the Dee is halted under the future scenario during the periods when the model is unable to make releases from Brenig and Celyn reservoirs in the upper part of the Dee catchment.

\section{Yield search}

The yield search shows results similar to the basic simulation but with more detail on individual sources. In general, the future scenario reveals an overall decrease in yield of $18.3 \%$ compared to the control, decreasing from $2358 \mathrm{Ml} \mathrm{d}^{-1}$ to $2033 \mathrm{Ml} \mathrm{d}^{-1}$. The contribution of individual sources to the overall yield is spatially highly variable; however, the take of individual sources shows an increase (decrease) of up to $80 \%(-77 \%)$ under the future climate change scenario (Table $2)$. There is reduced abstraction at most sources, as would be expected for a lower yield, with river and reservoir abstraction generally lower. Decreases in abstraction are particularly noticeable in Vyrnwy and the river Dee (22$33 \%$ ) in Wales, in the Longdendale reservoirs in the south Pennines (23\%) and in Haweswater in the Lake District (18\%) (Table 2). River abstractions decrease from most

Table 1. Comparison of statistics from the basic simulation runs for the control and future scenarios.

\begin{tabular}{|c|c|c|c|c|}
\hline & $\begin{array}{l}\text { CONTROL SCENARIO Run } \\
\text { Average (Ml for storage, } \\
\text { Ml } d^{-1} \text { for abstractions and } \\
\text { flows) }\end{array}$ & Days Full(\%) & $\begin{array}{l}\text { Future SCENARIo Run } \\
\text { Average (Ml for storage, } \\
\text { Ml } d^{-1} \text { for abstractions and } \\
\text { flows) }\end{array}$ & Days Full(\%) \\
\hline \multicolumn{5}{|l|}{ StORAGE } \\
\hline Haweswater & 81560.3 & 13.2 & 77998.6 & 15.0 \\
\hline Thirlmere & 39125.1 & 34.7 & 37470.7 & 31.0 \\
\hline Rivington & 15866.6 & 36.4 & 14893.9 & 27.4 \\
\hline Stocks & 11463.3 & 49.2 & 10769.7 & 40.5 \\
\hline Longdendale & 52029.9 & 47.4 & 47025.6 & 33.7 \\
\hline Vyrnwy & 49269.0 & 11.2 & 45046.5 & 9.9 \\
\hline \multicolumn{5}{|l|}{ Lake Abstraction } \\
\hline Ullswater & 55.8 & & 61.2 & \\
\hline Windermere & 99.9 & & 99.9 & \\
\hline \multicolumn{5}{|l|}{ River Abstraction } \\
\hline Lune & 40.4 & & 30.0 & \\
\hline Dee & 516.8 & & 515.5 & \\
\hline \multicolumn{5}{|l|}{ RIVER Flow } \\
\hline Pooley Br (Ullswater) & 638.7 & & 638.4 & \\
\hline Newby Br (Windermere) & 978.4 & & 1010.4 & \\
\hline
\end{tabular}




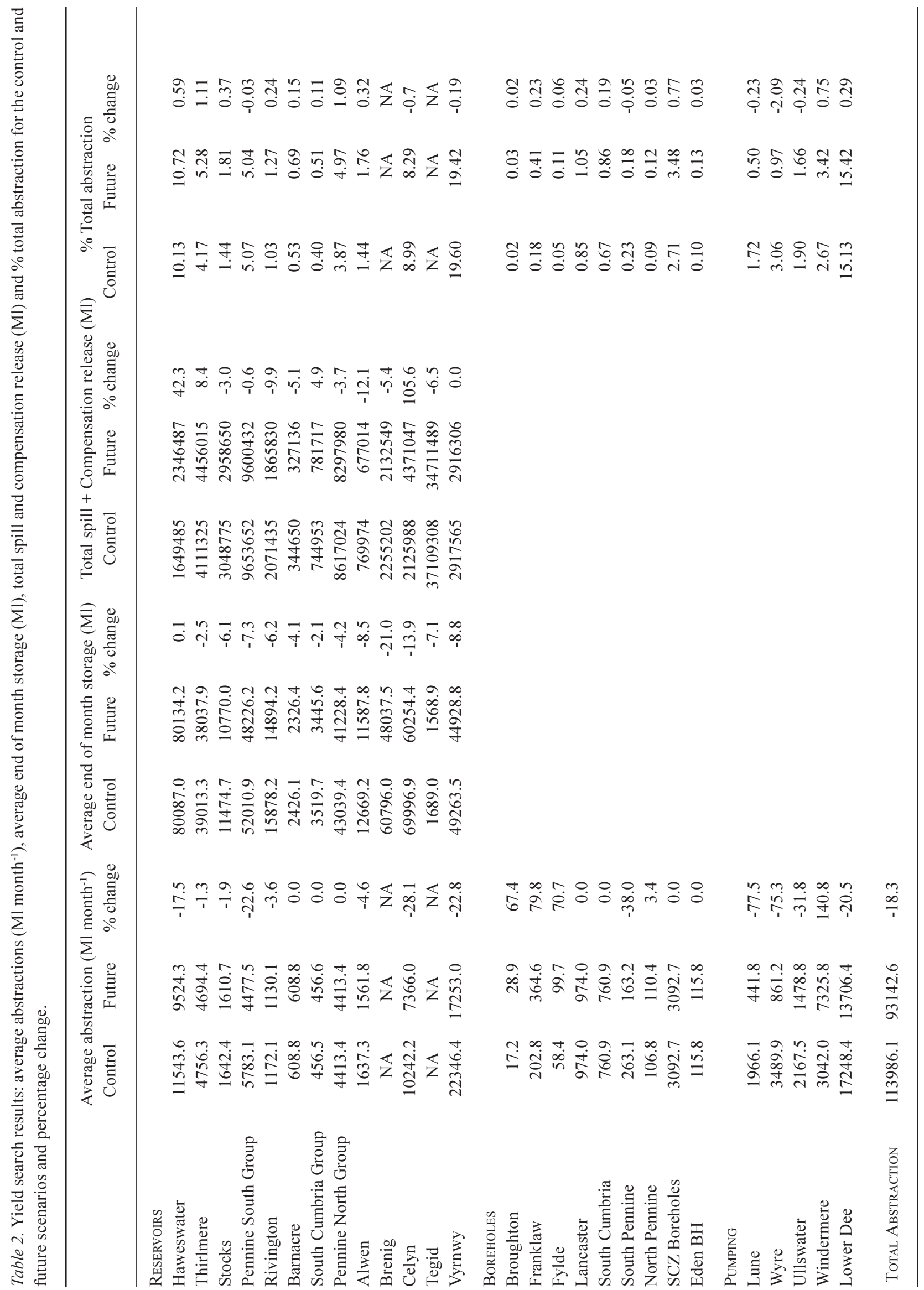


Table 3. Yield search results: summary of abstractions for each type of source for the control and future scenarios.

\begin{tabular}{lrrrr}
\hline & \multicolumn{3}{c}{$\begin{array}{c}\text { Abstraction from each type of source } \\
\text { Ml }\end{array}$} & \multicolumn{2}{c}{ \% Contribution } \\
Control & Future \\
& Control & Future & Contror & \\
\hline Total Reservoir & 80480.4 & 63618.6 & 71 & 72 \\
Total Borehole & 5591.7 & 5710.2 & 5 & 6 \\
Total River and Lake & 27913.9 & 23813.8 & 24 & 22 \\
Sum & 113986.1 & 93142.6 & 100 & 100 \\
\hline
\end{tabular}

sources, with abstractions from the rivers Lune and Wyre being reduced by over $70 \%$ under future climate change. However, despite the lower system yield overall, there are large increases in abstraction, 67-79\%, from the Franklaw and Broughton boreholes in the Fylde Area.

There is a small impact on the average end-of-month storage with $a<10 \%$ decrease at most reservoirs except for the Brenig and Celyn reservoirs in the River Dee catchment in North Wales, which show decreases of 13.9 and $21 \%$ respectively (Table 2). Many reservoirs also show a large increase in total spill and compensation releases under future climate change. In the Lake District, all reservoirs (Haweswater, Thirlmere) and lakes (Ullswater and Windermere) show increases of +3 to $+42 \%$ (Table 2 ). The largest increases are at Haweswater and could be a consequence of winter rainfall and flow increases and an increase in the magnitude of extreme flows (see Fowler and Kilsby, 2005).

In terms of the contribution of each source to the abstraction of the system overall, there is very little change under the future scenario (Table 2). The biggest decrease in abstraction is from the River Wyre $(-2.09 \%)$, with increasing abstractions from reservoirs at Thirlmere $(+1.11 \%)$ and the Pennine North Group (+1.09\%). Examination of the contribution to overall abstraction by the different groups of sources under the future scenario indicates (Table 3) a slight increase from reservoirs from 71 to $72 \%$, a small increase from boreholes from 5 to $6 \%$ and a decrease from rivers and lakes from 24 to $22 \%$.

\section{Discussion and conclusions}

This study highlights both the utility and flexibility of a conjunctive use water resource system. The contribution of individual sources to the overall yield is highly variable in space; individual sources show increases (decreases) in take of $\sim 80 \%$ ( $\sim 77 \%)$ under the SRES A2 future emissions scenario. The overall effect on system yield is lower; a reduction of only $18.3 \%$, but this has a significant impact on water supply reliability. Nevertheless, the flexibility of the system means that it is still able to meet the modelled demand of $2224 \mathrm{Ml} \mathrm{d}^{-1}$ for the most of the time under this climate change scenario, although this may not include the worst possible drought situation, even without a change in current control rules. However, peak demands may exceed this and the basic simulation runs indicate that the system would fail to meet demand for a few periods under the future climate. However, the flexibility of the system allows the demand to be met, even when the system is very close to its maximum yield, although this flexibility may be compromised under the future scenario. In fact, there is a significant difference in the mechanism controlling maximum yield between the control and future simulations. In the control scenario, the maximum system yield is controlled by the Lake District sources but, in the future scenario, the controlling influence is the Welsh sources. This suggests that substantial changes in the management of the IRZ water supply system may be essential under climate change. Mitigating the effects of climate change through alternative reservoir operating policies designed to mitigate reservoir system performance losses (Payne et al., 2004) will be investigated in a further study.

However, changes in abstraction licensing conditions, possibly as a result of various EU environmental directives such as the Habitats or Water Framework Directive, may lead to a decrease in take from individual sources that have, for example, a requirement for higher compensation releases or higher 'hands-off flows' (minimum acceptable flows below which no abstraction is allowed). Whether these individual changes are likely to be large enough to affect overall yield is, however, uncertain.

Although the IRZ is able to meet modelled demand most of the time under climate change, there is a cost implication of the change in usage of individual sources. In particular, additional pumping from boreholes in the Fylde area (Broughton, Franklaw and Fylde groups) (+67-79\%) will be much more expensive than abstracting water from gravity-fed reservoirs. Thus, under a future climate change, 
meeting current demand may be increasingly expensive an important conclusion for the future of water management in north-west England. To investigate the impact on cost further, optimisation runs would be required to examine revised operating rules to optimise cost. This will be the subject of further work.

There are some caveats to this modelling approach. Although it is customary for climate change studies to use 30 -year normal periods, such periods do not provide sufficient length of record to represent extreme events. Such events are crucially important in this study, since the droughts of 1995-1996 and 1928 are the standard 'design' events for system testing and optimisation. Excluding these events by using 1961-1990 as the normal period causes a major bias in the baseline for the system.

It is also important to examine the uncertainty in projected changes (Ekström et al., 2005). Here, results are presented for an impact study assessing a single climate change emissions scenario, the SRES A2 scenario (IPCC, 2000) from a single model, HadRM3H, and a single time-slice, 2070-2100, with pattern-scaling used to produce results for other emission scenarios and time-slices. This selection reflects the substantial computational cost associated with the double-nesting method used to produce the HadRM3H outputs as well as the computational expense and complications of interpretation of the Mospa model. The experimental design adopted for the UKCIP02 scenarios utilises a hierarchy of climate models (as explained earlier and in Hulme et al., 2002). The output from the coupled ocean-atmosphere HadCM3 experiments provided the boundary conditions to drive a high resolution $(\sim 120 \mathrm{~km})$ model of the global atmosphere, HadAM3H, and the outputs from these time-slice experiments (run over the period 2070$2100)$ provided the boundary conditions to drive the highresolution $(\sim 50 \mathrm{~km})$ regional model, HadRM $3 \mathrm{H}$. This double-nesting approach improves the quality of the simulated European climate, particularly the position of the major storm tracks but has the disadvantage that only the A2 SRES emissions scenario and the period 2070-2100 are simulated.

Uncertainty in climate change projections may result from many different areas, future emissions, model parameterisation and natural climate variability being just a few. This study does not examine uncertainties associated with modelling the climate system response to climate change or model parameterisation, as the only available high resolution simulations of future UK climate for the new IPCC SRES emissions scenarios come from the HadRM3H model. Climate change impacts are likely to be highly sensitive to small shifts in the position of the major storm tracks and these may be very different for large scale forcing using alternate climate models. Equally, as only one scenario is used, there is no quantification of the uncertainty associated with the chosen emissions scenario, A2, although the A2 scenario applied in the HadRM3H integrations is near the centre of the range of the new IPCC estimates in terms of mean global temperature change (Johns et al., 2003). Additionally, this study provides results from the first set of Mospa model runs. Further work is needed to understand model output in detail, although the principal methodology has been tested robustly here. In particular, more sophisticated rainfall-runoff modelling methods must be used to translate the B-C RCM inputs into inflows, testing whether the simple models used here are adequate to make the linkage between climate simulations and water management model or whether more physically-based hydrological models should be used. The results from this study are, therefore, illustrative of the impacts that can result from climate change, a plausible indication of the future, rather than a definitive projection of future hydrological impacts. However, it is hoped that water resources planners will respond to this challenge.

Further work will develop robust estimates of uncertainty to produce probabilistic estimates of the impacts of climate change on water resources in the north-west of England. A methodology first developed by Wigley and Raper (2001) and further advanced by Ekström et al. (2007c) for northwest England will be used. This combines probability distribution functions for global temperature increase (Wigley and Raper, 2001) and for scaling variables, such as the change in regional temperature/precipitation per degree of global annual average temperature change, to produce a probability distribution for regional temperature and precipitation.

Research is under way to assess whether Mospa can be adequately 'mimicked' by a computationally cheaper method, such as an artificial neural network, trained on a number of control and future simulations. Monte Carlo simulations using this technique could then be combined with probability distribution functions for north-west England (Ekström et al., 2007c) to assess uncertainty in the estimates of climate change produced using only one scenario. This would then allow a much larger range of scenarios and future operating policies to be assessed (Payne et al., 2004). In this way, it is hoped to provide a new methodology for the robust assessment of the impacts of climate change on water resource systems.

\section{Acknowledgments}

The authors would like to thank Hilary Smithers and Helen Stanley at the Environment Agency for their collaboration 
on this project and the supply of historic reservoir and river flow sequences, as well as John Sanders, Mike Stokes and Janet Makin from United Utilities who have been very helpful in providing both the Mospa model and discussing their climate change work. Historic rainfall series were obtained from the British Atmospheric Data Centre. The HadRM3H data have been supplied by the Climate Impacts LINK project (DEFRA Contract EPG 1/1/154) on behalf of the Hadley Centre and U.K. Met Office. This work is part of the SWURVE (Sustainable Water: Uncertainty, Risk and Vulnerability Estimation in Europe) project, funded under the EU Environment and Sustainable Development programme, grant number EVK1-2000-00075. Alan Hamlet and an anonymous reviewer made useful comments that helped to improve the manuscript.

\section{References}

Arnell, N.W., 1992. Impacts of climate change on river flow regimes in the UK. J. Inst. Water Environ. Manage., 6, 432442.

Arnell, N.W., 2003. Relative effects of multi-decadal climatic variability and changes in the mean and variability of climate due to global warming: future streamflows in Britain. J. Hydrol., 270, 195-213.

Arnell, N.W. and Reynard, N.S., 1996. The effects of climate change due to global warming on river flows in Great Britain. J. Hydrol., 183, 397-424.

Blaney, H.F. and Criddle, W.D., 1950. Determining water requirements in irrigated areas from climatological and irrigation data. USDA, Soil Conservation Service, TP-96.

Bryant, S.J., Arnell, N.W. and Law, F.M., 1994. The 1988-92 drought in its historical perspective. J. Chart. Inst. Water Eng., 8, 39-51.

Burlando, P. and Rosso, R., 2002a. Effects of transient climate change on basin hydrology. 1. Precipitation scenarios for the Arno River, central Italy. Hydrol. Process., 16, 1151-1175.

Burlando, P. and Rosso, R., 2002b. Effects of transient climate change on basin hydrology. 2. Impacts on runoff variability in the Arno River, central Italy. Hydrol. Process., 16, 1177-1199.

Christensen, N.S., Wood, A.W., Voisin, N., Lettenmaier, D.P. and Palmer, R.N., 2004. Effects of climate change on the hydrology and water resources of the Colorado river basin. Climatic Change, 62, 337-363.

Cubasch, U., von Storch, H., Waszkewitz, J. and Zorita, E., 1996. Estimates of climate change in Southern Europe derived from dynamical climate model output. Climate Res., 7, 129-149.

Duan, Q., Sorooshian, S. and Gupta, V.K., 1992. Effective and efficient global optimization for conceptual rainfall-runoff. Water Resour. Res., 28, 1015-1031.

Durman, C.F., Gregory, J.M., Hassell, D.C., Jones, R.G. and Murphy, J.M., 2001. A comparison of extreme European daily precipitation simulated by a global and a regional climate model for present and future climates. Quart. J. Roy. Meteor. Soc., 127, 1005-1015.

Ekström, M., Fowler, H.J., Kilsby, C.G. and Jones, P.D., 2005. New estimates of future changes in extreme rainfall across the UK using regional climate model integrations. 2. Future estimates and use in impact studies. J. Hydrol., 300, 234-251.
Ekström, M., Jones, P.D., Fowler, H.J., Lenderink, G., Buishand, T.A. and Conway, D., 2007a. Regional climate model data used within the SWURVE project 1: projected changes in seasonal patterns and estimation of PET. Hydrol. Earth Syst. Sci., 11, $1069-1083$

Ekström, M., Hingray, B., Mezghani, A. and Jones, P.D., 2007b. Regional climate model data used within the SWURVE project 2: addressing uncertainty in regional climate model data for five European case study areas. Hydrol. Earth Syst. Sci., 11, $1085-1096$

Fowler, H.J. and Kilsby, C.G., 2002. Rainfall and the North Atlantic Oscillation: A study of climatic variability in northern England. Int. J. Climatol., 22, 843-866.

Fowler, H.J. and Kilsby, C.G., 2004. Future increases in UK water resource drought projected by a regional climate model. In: Hydrology: Science \& Practice for the 21 st Century, Volume 1, Proc. Int. Conf., Imperial College London, UK, 12-16 July, British Hydrological Society. 15-21.

Fowler, H.J. and Kilsby, C.G., 2007. Using regional climate model data to simulate historical and future river flows in Northwest England. Climatic Change, 80, 337-367.

Fowler, H.J., Kilsby, C.G. and O'Connell, P.E., 2003. Modeling the impacts of climatic change and variability on the reliability, resilience and vulnerability of a water resource system. Water Resour. Res., 39, 1222, doi:10.1029/2002WR001778.

Fowler, H.J., Ekström, M., Kilsby, C.G. and Jones, P.D., 2005. New estimates of future changes in extreme rainfall across the UK using regional climate model integrations. 1: Assessment of control climate. J. Hydrol., 300, 212-233.

Giorgi, F., Hewitson, B., Christensen, J., Fu, C., Jones, R., Hulme, M., Mearns, L., Von Storch, H. and Whetton, P., 2001a. Regional climate information - evaluation and projections. In: Climate change 2001: The scientific basis. Contribution of Working Group I to the Third Assessment Report of the Intergovernmental Panel on Climate Change, J.T. Houghton, Y. Ding, D.J. Griggs, M. Noguer, P. van der Linden, X. Dai, K. Maskell and C.I. Johnson (Eds.), Cambridge University Press, Cambridge, UK. 583-638

Giorgi, F., Whetton, P., Jones, R., Christensen, J., Mearns, L., Hewitson, L., Von Storch, H., Francisco, R. and Jack, C., 2001b. Emerging patterns of simulated regional climatic changes for the $21^{\text {st }}$ century due to anthropogenic forcing. Geophys. Res. Lett., 28, 3317-3320.

Gordon, C., Cooper, C., Senior, C.A., Banks, H., Gregory, J.M., Johns, T.C., Mitchell, J.F.B. and Wood, R.A., 2000. The simulation of SST, sea ice extents and ocean heat transports in a version of the Hadley Centre coupled model without flux adjustments. Clim. Dynam., 16, 147-168.

Hay, L.E. and Clark, M.P., 2003. Use of statistically and dynamically downscaled atmospheric model output for hydrologic simulations in three mountainous basins in the western United States. J. Hydrol., 282, 56-75.

Hay, L.E., Clark, M.P., Wilby, R.L., Gutowski, W.J., Leavesley, G.H., Pan, Z., Arritt, R.W. and Takle, E.S., 2002. Use of regional climate model output for hydrologic simulations. $J$. Hydrometeorol., 3, 571-590.

Hewett, B.A.O., Harries, C.D. and Fenn, C.R., 1993. Water resources planning in the uncertainty of climate change: a water company perspective. In: Engineering for Climatic Change, R. White (Ed.). Thomas Telford, London, UK. 38-54,

Hulme, M., Jenkins, G. J., Lu, X., Turnpenny, J. R., Mitchell, T.D., Jones, R.G., Lowe, J., Murphy, J.M., Hassell, D., Boorman, P., McDonald, R. and Hill, S., 2002. In: Climate Change Scenarios for the United Kingdom: The UKCIP02 Scientific Report, Tyndall Centre for Climate Change Research, School of Environmental Sciences, University of East Anglia, Norwich, UK. 120pp 
IPCC, 2000. Technical Summary. In: Special Report on Emissions Scenarios, N.Nakicenovic and B. Swart, (Eds.), Cambridge University Press, Cambridge, UK. 570 pp.

Johns, T.C., Gregory, J.M., Ingram, W.J., Johnson, C.E., Jones, A., Lowe, J.A., Mitchell, J.F.B., Roberts, D.L., Sexton, D.M.H., Stevenson, D.S., Tett, S.F.B. and Woodage, M.J., 2003. Anthropogenic climate change for 1860 to 2100 simulated with the HadCM3 model under updated emissions scenarios. Clim. Dynam., 20, 583-612.

Kay, P.A., 2000. Measuring sustainability in Israel's water system. Water Int., 25, 617-623.

Lane, M.E., Kirshen, P.H. and Vogel, R.M., 1999. Indicators of impacts of global climate change on U.S. water resources. $J$. Water Resour. Plan Man..-ASCE, 125, 194-204.

Lettenmaier, D.P., Wood, A.W., Palmer, R.N., Wood, E.F. and Stakhiv, E.Z., 1999. Water resources implications of global warming: a US regional perspective. Climatic Change, 43, 537579.

Maier, H.R., Lence, B.J., Tolson, B.A. and Foschi, R.O., 2001. First-order reliability method for estimating reliability, vulnerability, and resilience. Water Resour. Res., 37, 779-790.

Marsh, T.J., 1996. The 1995 drought - a signal of climatic instability? Proc. Inst. Civil Eng.-Water, 118, 189-195.

Marsh, T.J., 2001. The 2000/2001 floods in the UK - a brief overview. Weather, 56, 343-345.

Marsh, T.J. and Monkhouse, R.A., 1993. Drought in the United Kingdom, 1988-92, Weather, 48, 15-22.

Marsh, T.J. and Turton, P.S., 1996. The 1995 drought - a water resources perspective, Weather, 51, 46-53.

Mearns, L.O., Bogardi, I., Giorgi, F., Matyasovzsky, I. and Palecki, M., 1999. Comparison of climate change scenarios generated from regional climate model experiments and statistical downscaling. J. Geophys. Res., 104, 6603-6621.

McGuffie, K., Henderson-Sellers, A., Holbrook, N., Kothavala, Z., Balachova, O. and Hoekstra, J., 1999. Assessing simulations of daily temperature and precipitation variability with global climate models for present and enhanced greenhouse climates. Int. J. Climatol., 19, 1-26.

Nash, J.E. and Sutcliffe, J.V., 1970. River flow forecasting through conceptual models. Part I - A discussion of principles. J. Hydrol., 10, 282-290.

Payne, J.T., Wood, A.W., Hamlet, A.F., Palmer, R.N. and Lettenmaier, D.P., 2004. Mitigating the effects of climate change on the water resources of the Columbia river basin. Climatic Change, 62, 233-256.
Pilling, C. and Jones, J.A.A., 1999. High resolution climate change scenarios: implications for British runoff. Hydrol. Process., 13, 2877-2895.

Pilling, C.G. and Jones, J.A.A., 2002. The impact of future climate change on seasonal discharge, hydrological processes and extreme flows in the Upper Wye experimental catchment, midWales. Hydrol. Process., 16, 1201-1213.

Pope, V.D., Gallani, M.L., Rowntree, P.R. and Stratton, R.A., 2000 The impact of new physical parameterizations in the Hadley Centre climate model - HadAM3. Clim.Dynam., 16, 123-146.

Prudhomme, C., Reynard, N. and Crooks, S., 2002. Downscaling of global climate models for flood frequency analysis: where are we now? Hydrol. Process., 16, 1137-1150.

Schär, C., Vidale, P.L., Lüthi, D., Frei, C., Häberli, C., Liniger, M.A. and Appenzeller, C., 2004. The role of increasing temperature variability in European summer heatwaves. Nature, 427, 332-336.

Todini, E., 1996. The ARNO rainfall-runoff model. J. Hydrol. 175, 339-382.

Van Rheenen, N.T., Wood, A.W., Palmer, R.N. and Lettenmaier, D.P., 2004. Potential implications of PCM climate change scenarios for Sacramento - San Joaquin river basin hydrology and water resources. Climatic Change, 62, 257-281.

Vogel, R.M., Lane, M., Ravindiran, R.S. and Kirshen, P., 1999. Storage reservoir behaviour in the United States. J. Water Resour. Plan. Man..-ASCE, 125, 245-254.

Walker, S., 1998. Sustainable water resources management beyond the 1995-96 drought. Proc. Inst. Civil Eng.-Water, 130, $207-$ 216.

Walsh, C. and Kilsby, C.G., 2007. Impacts of climate change on flow regime affecting Atlantic salmon. Hydrol. Earth Syst. Sci., 11, 1127-1143.

Wardlaw, R.B., Hulme, M. and Stuck, Y., 1996. Modelling the impacts of climate change on water resources. J. Chart. Inst. Water Eng., 10, 355-364.

Wigley, T.M.L. and Raper, S.C.B., 2001. Interpretation of high projections for global-mean warming. Science, 293, 451-454.

Wilby, R.L., Hay, L.E., Gutowski, W.J., Arritt, R.W., Takle, E.S., Pan, Z., Leavesley, G.H. and Clark, M.P., 2000. Hydrological responses to dynamically and statistically downscaled climate model output. Geophys. Res. Lett., 27, 1199-1202.

Wood, A.W., Lettenmaier, D.P. and Palmer, R.N., 1997. Assessing climate change implications for water resources planning. Climatic Change, 37, 203-228.

Wood, A.W., Leung, L.R., Sridhar, V. and Lettenmaier, D.P., 2004. Hydrologic implications of dynamical and statistical approaches to downscaling climate model outputs. Climatic Change, 62, $189-216$. 